\title{
ANALYSIS OF THE LUMINOUS FIELD IN FLUORESCENT OPTICAL LAYERS WITH QUANTUM DOTS BASED ON CDSE/CDS/ZNS
}

\author{
Sergei A. Pavlov, Alexei S. Pavlov, Elena Yu. Maksimova, Anton V. Alekseenko, \\ Alexander V. Pavlov, and Eugene M. Antipov
}

D. Mendeleev University of Chemical Technology of Russia, Moscow E-mails:chemlab.info@yandex.ru,maksimovalkm@yandex.ru

\begin{abstract}
The structure of a luminous field in a fluorescence layer containing $C d S e / C d S / Z n S$-based quantum dots and acting as a transducer ${ }^{1}$ in an optical fluorescent sensor is described on the basis of three-flux approximation. Differential equation system of three-flux approximation is solved by numerical technique. It is found that diffuse reflectance ${ }^{2}$ of the layer extremely depends on concentration of quantum dots in the layer and its physical thickness. Optimal parameters of the layer required for forming of maximum analytical layer are determined.

Keywords: optical sensors, fluorescence, quantum dots, optics of fluorescence layer

One of directions of development of contemporary analytical chemistry is development of sensor devices allowing to make operative analysis with high precision in real time with minimal sample preparation. Such devices have been being introduced in medicine, biology, biochemistry and ecology [1-3] for analysis of both gaseous and liquid media. Of special interest are optical fluorescent sensors which are characterised with simplicity, multi-purposes, high sensitivity and precision of measurements.

\footnotetext{
1 Transducer is a device transforming visible changes (of physical or chemical nature) into a measurable signal [1].

2 All light engineering magnitudes in the article are implied to be spectral ones. - Ed. Note.
}

Development of contemporary methods of synthesis of new types of semi-conductor colloid phosphors based on cadmium and zinc chalcogenides like $C d S e / C d S / Z n S$ - the so-called quantum dots (QD) - has opened new prospects in development of a generation of optical sensor devices of this type. These substances have a number of unique optical and physical and chemical properties, primarily high photostability and energy-efficient fluorescence in visible and near infrared regions of spectrum.

One of important distinctions of the reviewed QD's is high dependence of their fluorescent properties on chemical environment. For example, experience has shown that these properties are very sensitive to interfacial processes proceeding in case of adsorption of molecular oxygen, water, ammonia, hydrogen chloride, hydrogen peroxide, molecular bromine, and iodine, and many other substances on the surface of quantum dots (see, for example, [4-7]). Despite high practical importance, the mechanisms of the fluorescence quenching processes are not studied well currently [8], but it does not prevent application of QD's for our purposes. Besides, we have found that not only the level of fluorescent radiation is subject to sufficient changes in various media, but also electrophysical properties (in particular, dielectric losses, dielectric capacity and conductance) are [9].

The processes of fluorescence quenching are the most interesting processes for application in sensors as they reduce radiation by sensitive layer. Among the most efficient quenchers, there are ions of heavy 
metals, halogens in molecular form, paramagnetic ions and molecules as well as acceptors of electron excitation [10]. Effect of fluorescence quenching by means of molecular iodine $I_{2}$ was used by us for development of a fluorescent sensor based on this entity [11]. The quenching effects were used also in structures of sensors for analysis of a number of chemical entities: hydrogen peroxide, ions of heavy metals, molecules of halides, colourants, polar solvents, and many others.

During manufacturing of a sensing element, QDs are introduces in suitable matrices (both polymer and porous non-organic ones). The prepared sensing layers should be placed in a measure cell allowing to perform excitation and registration of photo luminescence and probably to study some of its other properties such electrical (and dielectric), dielectric capacity, dielectric conductance and dielectric losses. What is critically important here is that the sensitive layer should be available for target external influence such as contacts with analysed gaseous or liquid medium and irradiation by exciting radiation as well as for correct registration of emitted radiation. A laser or a LED with required radiation wavelength may be used as a source of exciting radiation. A typical structural diagram of a sensor is shown in Fig. 1.

This article describes calculation of luminous fields in a sensitive layer of a transducer in order to determine optical characteristics required for obtainment of optimal analytical signal such as concentration of photoactive component, optical thickness of a layer, radiance of exciting radiation, capability to diffuse light and conditions of reflection from the borders of a layer. The target parameter here is radiance of the emitted (upwelling) radiation in direction of a radiation detector.

Then, to obtain radiance of radiation reflected from a flat optical layer, we use some representations of multi-flux approximation. For instance, for a non-fluorescent infinite flat layer, it is possible to use two-flux approximation proposed by M.M. Gurevich [12] and then developed by P. Kubelka and F. Munk [13] where a field may be described by the following system of differential equations:

$$
\begin{aligned}
& \frac{d I_{1}(x)}{d x}=-(k+s) I_{1}+s I_{2}(x), \\
& \frac{d I_{2}(x)}{d x}=s I_{1}(x)-(k+s) I_{2}(x),
\end{aligned}
$$

where $k$ and $s$ are absorption and diffusion indexes, $I_{1}(x)$ and $I_{2}(x)$ are radiances of incident and upwelling radiation inside a layer in a plane with $x$ coordinate.

The system (1) has an analytical solution [14] which, in particular, derives general reflectance of a flat layer $\mu$ with physical thickness $d$ :

$$
\ln \frac{\left(\mu-a-\sqrt{a^{2}-1}\right)\left(\mu^{\prime}-a+\sqrt{a^{2}-1}\right)}{\left(\mu^{\prime}-a-\sqrt{a^{2}-1}\right)\left(\mu-a+\sqrt{a^{2}-1}\right)}=2 k d \sqrt{a^{2}-1},
$$

where $\mu^{\prime}$ is the reflectance of the upper border of the layer and $a=1+s / k$.

Then we use a three-flux Kubelka-Munk model where distribution of radiation inside a medium (layer) is represented as differential-difference equations for three components of this radiation according to $[15,16]$ :

$$
\begin{gathered}
\frac{d F_{1}(x)}{d x}=-(k+s) F_{1}(x), \\
\frac{d F_{2}(x)}{d x}=-\left\{2 k+\frac{3}{4}[k+s(1-g)]\right\} F_{2}(x)+ \\
\left.+\frac{3}{4}[k+s(1-g)] F_{3}(x)\right]+\frac{s}{4}(2+3 g) F_{1}(x),
\end{gathered}
$$

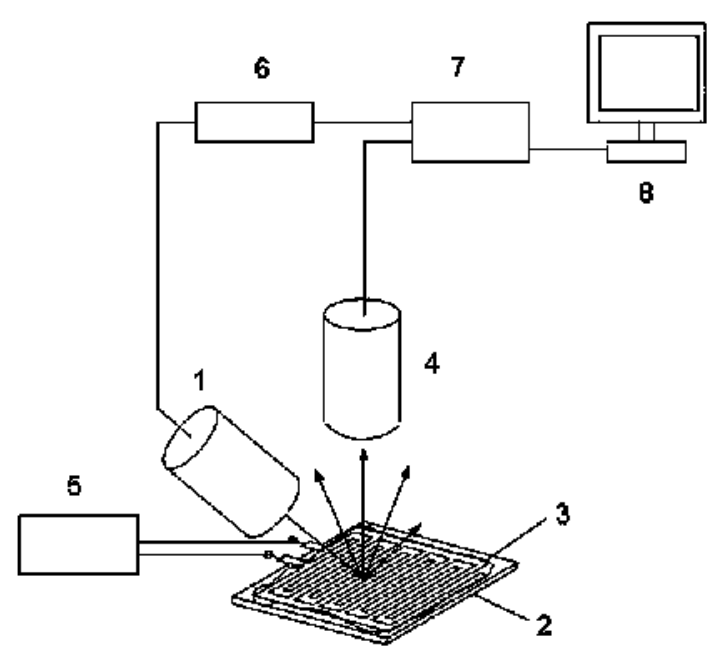

Fig. 1. Diagram of the fluorescent sensor for simultaneous measurements of radiance and a number of electrophysical parameters of the fluorescent sensitive layer: 1 - the source of exciting radiation; 2 - coplanar cell with interdigitated structure on a neutral base; 3 - sensitive layer; 4 - diffused radiation detector; 5 - dielectric characteristics measuring device; 6 - exciting radiation source (LED or laser) control unit; 7 - spectrometer; 8 - computer 


$$
\begin{gathered}
\frac{d F_{3}(x)}{d x}=\left\{2 \mathrm{k}+\frac{3}{4}[k+s(1-g)]\right\} F_{3}(x)- \\
-\frac{3}{4}[k+s(1-g)] F_{2}(x)-\frac{s}{4}(2-3 g) F_{1}(x),
\end{gathered}
$$

where $F_{1}(x)$ is the radiance of collimated exciting incident radiation, $F_{2}(x)$ is the radiance of diffused incident radiation, $F_{3}(x)$ is the radiance of diffused upwelling radiation, $g$ is the diffusion anisotropy factor.

The boundary conditions for this system are as follows:

$$
\begin{gathered}
F_{1}(0)=\left(1-r_{1, \mathrm{\phi p}}\right) F_{10}, \\
F_{2}(0)=\left(1-r_{1, \phi \mathrm{p}}\right) F_{10}+r_{\mathrm{BH}} F_{3}(d), \\
F_{3}(d)=r_{\mathrm{BH}} F_{2}(d),
\end{gathered}
$$

where $F_{10}$ is the radiance of collimated exciting incident radiation at the upper border of the layer, $F_{3}(0)$ is the radiance of diffused upwelling radia-
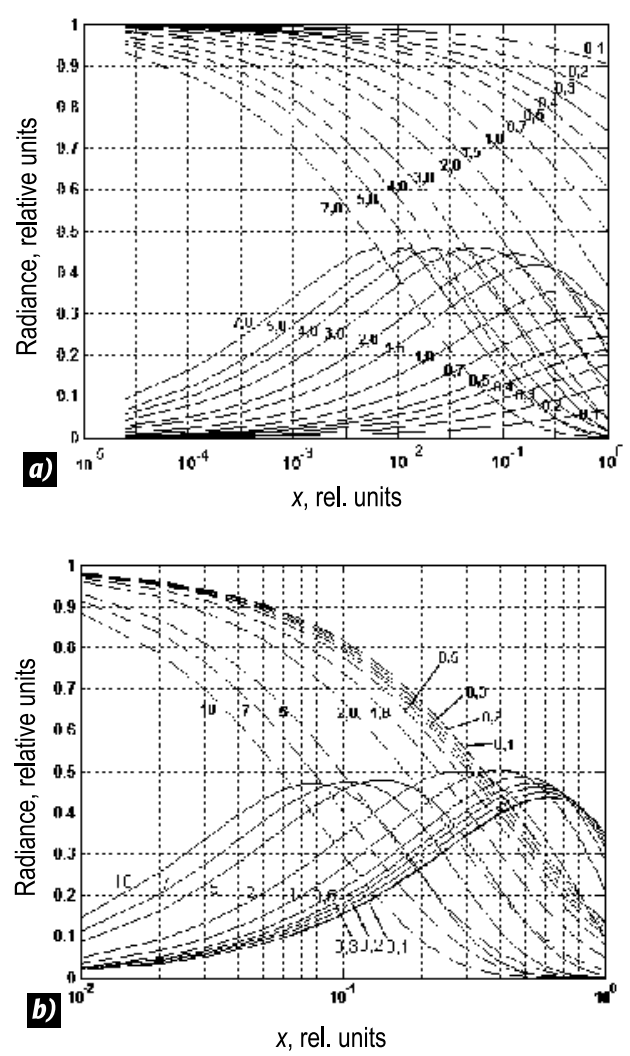

Fig. 3. Luminous field in a non-diffusing, $s=0 \mathrm{~mm}^{-1}$, (a), and diffusing, $s=2 \mathrm{~mm}^{-1},(b)$, fluorescent layers. The dashed lines are the curves of radiance of collimated exciting incident radiation $F_{1}(x)$, continuous lines are curves of radiance of diffused upwelling radiation $F_{3}(x)$ forming the analytical signal of the transducer. The numbers near the curves are the relevant values of $k\left(\mathrm{~mm}^{-1}\right)$ tion at the upper border of the layer, $F_{2}(d)$ is the radiance of diffused incident radiation at the lower border of the layer, $r_{1, \phi p}$ is the Fresnel reflection coefficient, $r_{\mathrm{BH}}$ is the internal reflectance of both borders of the layer.

It is worth noting that, unlike the system (1), the system (2) doesn't have an analytical solution and reflectance coefficients included in it may be calculated using relevant Fresnel formulas [17].

Introduction of phosphor in the layer sufficiently complicates distribution of radiation inside it. Herewith, the system of equations (2) should be supplemented by item $f(\mathrm{x})$ :

$$
f(x)=\frac{1}{2} k_{1} \mathrm{f} \cdot\left[F_{1}(x)+F_{2}(x)+F_{3}(\mathrm{x})\right],
$$

where $k_{1}$ is the absorptance at wavelength of fluorescence excitation, $f$ is the fluorescence quantum efficiency.

It can be noted that introduction of QD's as a photoactive component causes intensive absorption in the blue region of spectrum. Peak of radiation in a used fluoropolymer matrix is near excitonic absorption (Fig. 2). Addition of fluorescent component to the equation system (2) gives the following result:

$$
\begin{gathered}
\frac{d F_{1}(x)}{d x}=-(k+s) F_{1}(x), \\
\frac{d F_{2}(x)}{d x}=-\left\{2 k+\frac{3}{4}[k+s(1-g)]\right\} F_{2}(x)+ \\
\left.+\frac{3}{4}[k+s(1-g)] F_{3}(x)\right]+\frac{s}{4}(2+3 g) F_{1}(x)+ \\
+\frac{1}{2} f k_{1}\left[F_{1}(x)+F_{2}(x)+F_{3}(x)\right] \\
\frac{d F_{3}(x)}{d x}=\left\{2 k+\frac{3}{4}[k+s(1-g)]\right\} F_{3}(x)- \\
-\frac{3}{4}[k+s(1-g)] F_{2}(x)-\frac{s}{4}(2-3 g) F_{1}(x)+ \\
+\frac{1}{2} f \cdot k_{1}\left[F_{1}(x)+F_{2}(x)+F_{3}(x)\right] .
\end{gathered}
$$

Analytical solution of the equation system (3) is impossible and its computational solution was performed using MATLAB ode 45 procedure with relative accuracy of $0.1 \%$ specified by default (The procedures of solving differential equations using this software are well-known [18]). 


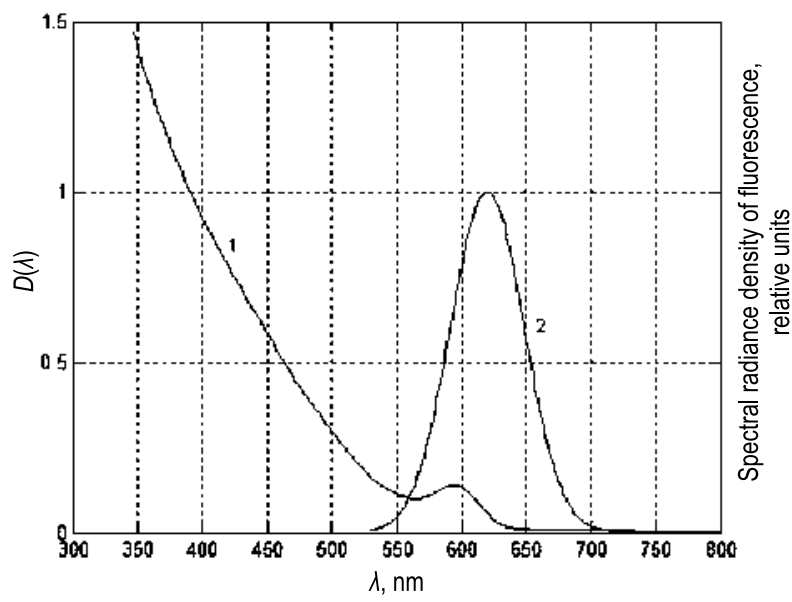

Fig. 2. Spectral optical density (1) and spectral radiance of fluorescent radiation (2) of the sensitive layer based on the fluorine-containing polymer film containing $\mathrm{CdSe} / \mathrm{CdS} / \mathrm{ZnS}$ quantum dots

Analysis of radiation distribution in the fluorescent layer, in particular, allowed us to optimise light-converting layers used as cover materials [19] and to obtain major conformities of formation of chromaticity of optical materials containing $C d S e / C d S / Z n S$ QDs with different wavelength of upwelling radiation [20]. The results of calculations performed in this study show, in particular, that the analytical function $F_{3}(x)$ has extremum nature (Fig. 3). The example presented in Fig. 4 shows that the level of a relevant analytical signal characterised with a value of $F_{3}(0)$ is maximal with physical thickness of layer equal to $2 \mathrm{~mm}$. (Increase of thickness in excess of this value causes reduction of signal amplitude, which is thought to be important for development of fluorescent sensors).

The calculations made show that, in order to amplify the signal $F_{30}$, it is necessary to optimise the value of $s$, which is rather practicable, so the matrix should be porous for efficient operation of transducer. Consideration of absorption of exciting radiation as well as fluorescent flux by the photoactive component shows that $F_{3}(0)$ is extremum depending on both concentration of QDs in the matrix and $d$. Measurements using a sensor with a sensitive layer based on a porous fluorine-containing co-polymer has shown that optimal concentration of QDs is 1.5 $\mathrm{mg} / \mathrm{g}$ with thickness of the sensitive layer of $2 \mathrm{~mm}$. Increase of concentration of the photoactive component and $d$ as compared to these values causes reduction of $F_{3}(0)$, i.e. general reflectivity of the layer.

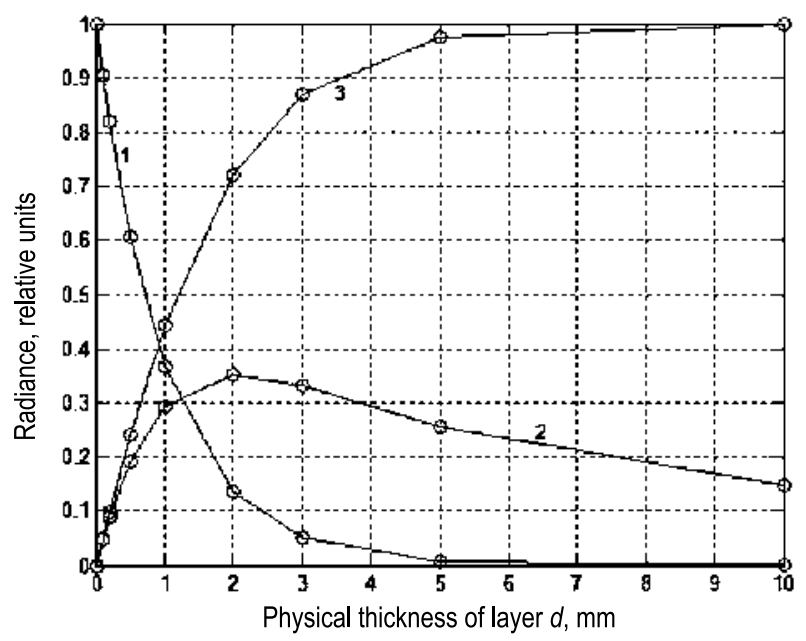

Fig. 4. Dependences of boundary radiances of radiation $F_{1}(d)(1), F_{3}(0)(2)$ и $F_{2}(d)(3)$ on physical thickness of layer $d$

\section{CONCLUSION}

1. Analysis of a luminous field of a sensitive element of the fluorescent sensor based on $\mathrm{CdSe} / \mathrm{CdS} /$ $\mathrm{ZnS}$ quantum dots has been performed. The computational scheme based on the system of three differential equations considering radiances of incident exciting, incident diffused and general upwelling radiation has been used.

2. Computational methods of solving the equation system have been developed and the structure of the luminous field in the layer has been determined. Major conformities of formation of radiance of general upwelling radiation, which should be used for formation of an analytical signal of a sensor, have been found.

3. It has been found that radiance of the general upwelling radiation of a layer is extremum dependent on both concentration of QDs in the material and on physical thickness of the sensitive layer. Optimal dimensions of the sensitive layer required for its efficient application as a transducer has been proposed.

\section{ACKNOWLEDGMENT}

The study was performed with financial support of the Ministry of Education and Science of the Russian Federation. Grant Agreement 14.574.21.0185 (ID of applied scientific research (project) RFMEFI57417X0185). 


\section{REFERENCES}

1. Atkins B. Chemical and Biological Sensors. Moscow: Tekhnosfera, 2005.

2. Bio-sensors: Basics and Applications / Edited by E. Turner, I. Karube and J. Wilson. Moscow: Mir, 1992.

3. Otto M. Contemporary Methods of Analytical Chemistry (in 2 volumes). Moscow: Tekhnosfera, 2004, 416 p. (vol.1), 288 p. (vol. 2).

3. Otto M. Sovremennyie metody analiticheskoi khimii (2 volumes). M: Tekhnosfera, 2004, 416 p. (vol.1), 288 p. (vol. 2).

4. Cordero S.R., Carson P.J., Estabrook R.A., Strouse G.F., Buratto S.K. Photo-Activated Luminescence of CdSe Quantum Dot Monolayers // J. Phys. Chem. B. 2000, Vol. 104, pp. 12137-12142.

5. Uematsu T., Maenosono S., Yamaguchi Y. Photoinduced fluorescence enhancement in $\mathrm{CdSe} / \mathrm{ZnS}$ quantum dot sub-monolayers sandwiched between insulating layers: influence of dot proximity // J. Phys. Chem. B. 2005, Vol. 109, pp. 8613-8618.

6. Pechstedt K., Whittle T., Baumberg J., Melvin T. Photoluminescence of colloidal CdSe/ $\mathrm{ZnS}$ quantum dots: the critical effect of water molecules // J. Phys. Chem. C. 2010, Vol. 114, No. 28, pp. 12069-12077.

7. Ito Y., Matsuda K., Kanemitsu D. Photoluminescence intermittency in single CdSe nanoparticles: environment dependence // J. Lumin. 2008, Vol. 128, No. 5-6, pp. 868-870.

8. Non-equilibrium processes in sensor structures / Edited by V.A. Smyntyna. Odessa: ONU, 2015.

9. Pavlov S.A., Pavlov A.S., Maksimova E. Yu., Alekseenko A.V., Pavlov A.V., Antipov E.M. Application of $\mathrm{CdSe} / \mathrm{CdS} / \mathrm{ZnS}$ quantum dots in coplaner capacity structures for optical sensors in liquid and gaseous me$\mathrm{dia}^{3}$ // Applied Physics. 2018, \# 3, pp. 27-32.

9. Pavlov S.A., Pavlov A.S., Maksimova E. Yu., Aleksrenko A.V., Pavlov A.V., Antipov E.M. Ispol'zovaniie kvantovykh tochek na osnove $\mathrm{CdSe} / \mathrm{CdS} / \mathrm{ZnS}$ v komplanarnykh emkostnylh strukturakh dlia opticheskikh datchikov zhidkikh i gazovykh sredakh. // Prikladnaia fizika. 2018, Issue 3, pp. 27-32.

10. Vladimirov Yu.A., Potapenko A. Ya. Physical and chemical basics of photo-biological processes. Moscow: Vysshaya Shkola, 1989, 199 p.

10. Vladimirov Yu.A., Potapenko A. Ya. Fiziko-khimicheskiie osnovy fotobiologicheskikh protsessov. - M: Vysshaya Shkola, 1989, 199 p.

\footnotetext{
${ }^{3}$ Publication name is kept. - Ed. Note.
}

11. Pavlov S.A., Pavlov A.S., Maksimova E. Yu., Alekseenko A.V., Pavlov A.V., Antipov E.M. Fluorescent sensor based on $\mathrm{CdSe} / \mathrm{CdS} / \mathrm{ZnS}$ quantum dots for analysis of $\mathrm{I} 2$ in gaseuos and water and spirit media // Applied Physics. 2018, Issue 5.

11. Pavlov S.A., Pavlov A.S., Maksimova E. Yu., Alekseenko A.V., Pavlov A.V., Antipov E.M. Liuminiscentnyi sensor na kvantovykh tochkakh $\mathrm{CdSe} / \mathrm{CdS} /$ ZnS dlia analiza $\mathrm{I}_{2} \mathrm{v}$ gazovykh i vodno-spirtovykh sredakh. // Prikladnaia fizika. 2018, \# 5.

12. Gurevich M. Ueber eine Rationelle Klassification der Lichtstreuenden Medien // Physik. Zeitschr, 1930, Bd. 31, pp. 753-763.

13. Simonot L., Thoury M., Delaney J. Extension of the Kubelka-Munk theory for fluorescent turbid media to a nonopaque layer on a background // J. Opt. Soc. Am. A. 2011, Vol. 28, No. 7, pp. 1349-1357.

14. Kubelka P., Munk F. Ein Beitrag zur optic der farbanstriche // Z. Techn. Phys. 1931, Bd. 12, \# 11a, pp. 593-601.

15. Giraev K.V., Ashurbekov N.A., Kobzev O.V. Optical research of bio-tissues: determination of absorption and scattering coefficients// Letters to the Journal of Technical Physics, 2003, Vol.29, \#21, pp. 48-52.

16. Remisowsky A.M.V., McClendon J.H., Fukhansky L. Estimation of the optical parameters and light gradients in leaves: multi-flux versus two-flux treatment // Photochemistry and Photobiology, 1992, Vol.55, \#6, pp. 857-865.

17. Kizel V.A. Light reflection. Moscow: Nauka, 1973, $351 \mathrm{p}$.

17. Kizel V.A. Otrazheniie sveta. M: Nauka, 1973, $351 \mathrm{p}$.

18. Shampine L., Gladwell I., Thompson S. Solving ODEs with MATLAB. Saint-Petersburg [and others]: Lan, 2009, 299 p.

19. Sergei A. Pavlov, Sergei L. Koryakin, Natalia E. Sherstenyova, ElenaYu. Maksimova, and Antipov Eugene M. Highly Effective Covering Materials with Quantum Dots for Greenhouses// Light \& Engineering Journal, Vol. 26, 2018, \#2, pp.36-51.

20. Evgeny M. Antipov, Sergey L. Koryakin, Elena Yu. Maksimova, Sergey A. Pavlov, and Sherstnyova Natalya E. Features of the Formation of Radiation Chromaticity by the Dispersion of CdSe/CdS/ZnS Quantum Dots in Multicomponent Systems// Light \& Engineering Journal, 2017, Vol. 25, \#3, pp.244-249. 


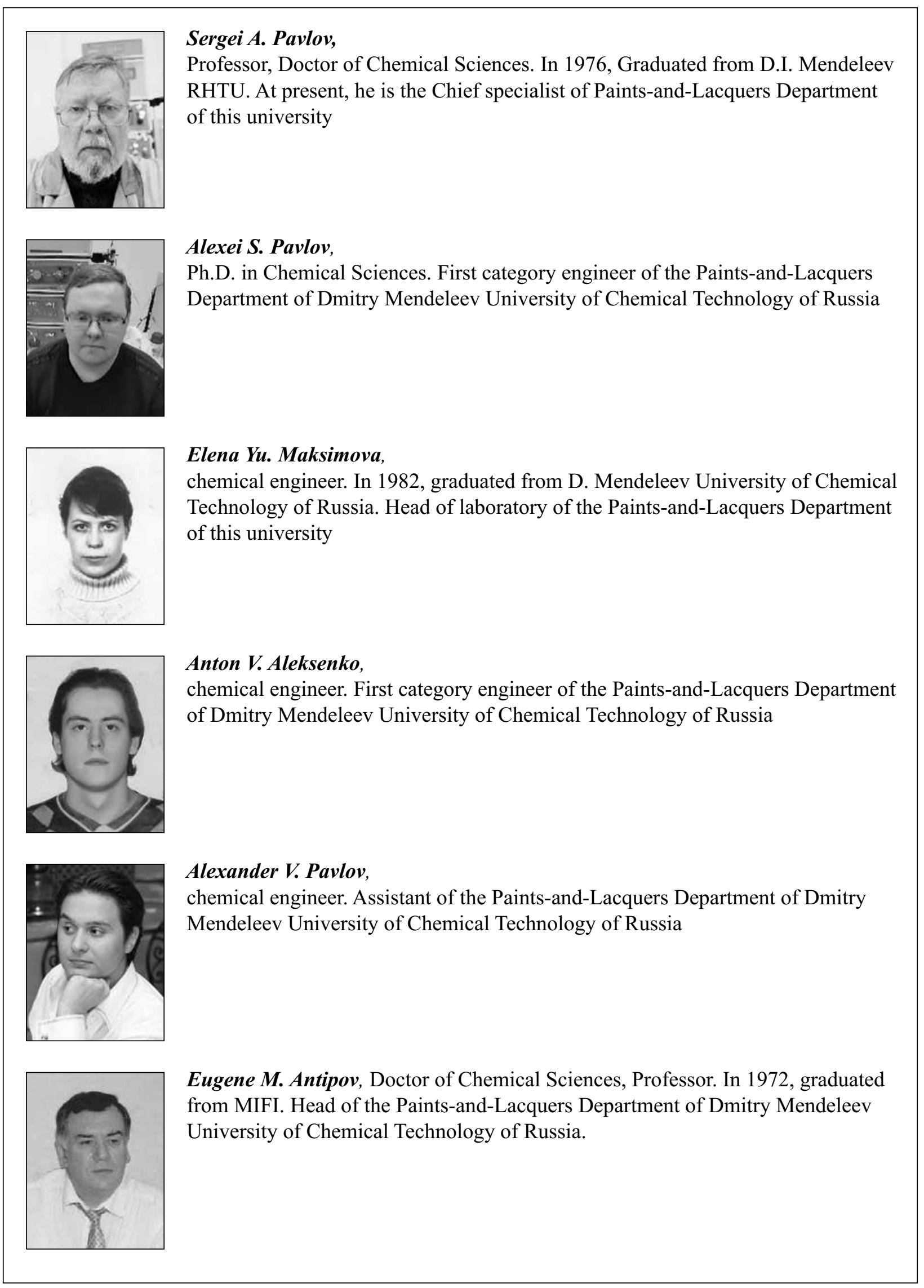

